\title{
Novel combined approach for bedrock incision analysis: geochemistry and hydraulic modelling. Loire River Application (France)
}

\author{
M. Tombozafy ${ }^{1}$, D. Mimoun ${ }^{1}$, M. Batton-Hubert ${ }^{1}$, D. Graillot ${ }^{1}$, \\ D. Garcia ${ }^{2}$ \& A. Aoufi ${ }^{3}$ \\ ${ }^{1}$ Centre SITE, Ecole Nationale Supérieure des Mines de Saint Etienne, \\ France \\ ${ }^{2}$ Centre SPIN, Ecole Nationale Supérieure des Mines de Saint Etienne, \\ France \\ ${ }^{3}$ Centre SMS, PECM UMR 5146, ENMSE, Saint Etienne, France
}

\begin{abstract}
The goal is to accurately forecast or understand erosion and deposition in bedrock river channels. The Loire River (France) was chosen as a case study. Like most European major rivers, the Loire presents an accelerated incision ( $2.5 \mathrm{~m}$ during the last 150 years). Current models are limited because they can only accurately simulate aggradation and degradation on alluvial river containing non-cohesive and cohesive sediments. In our case, these models are not efficient along the whole length of this river. This is because of the outcropping of bedrock. This obstacle led us to establish a new manner to characterize bedrock incision not only by particle impacts but also considering stream flow intensity. To complete this work, we use the geochemical signature of transported materials to quantify the amount of substratum eroded between two sampled areas. This allows us to validate the results of the hydraulic model.
\end{abstract}

Keywords: sediment transport, bed-load, stream flow, geochemistry, erosion, bedrock outcrop, numerical scheme.

\section{Introduction}

The consequences of river incision are multiple: bridge scouring and structure failure, dam breaks, deeper lowest water levels, decreasing water tables, ripariale 
vegetation development... In case of vegetation overgrowth, a decrease in the stream or river's velocity engenders more deposition and tends to raise the height of riverbanks, leading to a more channelized stream (Belleudy [1]).

Many techniques have been used to analyze riverbed incision problems as shown in this brief overview. Schaller et al. [2] performed rock surfaces datation by cosmogenic nuclide. They estimated the incision rates over time of the Taroko River (Taiwan) using the exposure age of fluvially sculpted surfaces and their altitude above the active river channel. Bourke [3] used suspended sediment concentration (SSC) data to study the geomorphic effect of sub-bankfull flow in a central Australian stream. Moreover, during the two last decades, a lot of computer programs like HEC-6 (Thomas and Prashum [4]), SEDICOUP (Holly and Rahuel [5]), TELEMAC-2D (Hervouet [6]) have been developed. The precision of these models allows searchers and engineers to simulate complicated situations and to obtain results not so far from on site observations.

Evaluating the transport, erosion and sedimentation is a key element for describing and understanding the behavior of rivers, and for sustainable use of water resources and associated infrastructures. Within the framework of the project: Plan Loire Grandeur Nature (PLGN), we performed numerical calculations along a $50 \mathrm{~km}$ span of the Loire River, located between the Grangent and Villerest dams.

The intensity of the incision phenomena insures that marly materials are visible along more than $30 \%$ of the studied stretch. Due to some limits of sediment transport formulas, and the uncertainty of in-situ measurements, we intend to develop a geochemical approach to evaluate the proportion of tertiary material eroded along the concerned sector of the Loire River.

In this paper, we present the one-dimensional model that we produced to simulate flow and sediment transport in the Loire River. We also demonstrate a proposed method for geochemical approach.

\section{Model description}

This one-dimensional model has two components: one to simulate the flow and another to characterize the changes in river morphology due to erosion or deposition of sediment. Equations for steady and unsteady flow are employed. In case of steady flow, the energy equation is resolved by the backwater method to obtain the water level at any point along the longitudinal profile. If the Froude Number $F r>1$ (supercritical flow regime), then the calculation is performed from upstream to downstream. Otherwise, if $F r<1$ (subcritical flow regime), then the calculation should begin in the downstream part of the reach.

If the canal characteristics vary considerably from one section to another, or if the flow is variable in time, then the model resolves the Barré-De-Saint-Venant equations.

The following assumptions are used (Cunge et al. [7], Soni et al. [8]): -channel flow is assumed to be strictly one-dimensional, i.e. there is a uniform velocity over the cross section and the water level considered horizontal or flat along the length of the streambed. 
-river curvature is small and vertical acceleration is negligible, hence the pressure is hydrostatic

-effects of boundary friction and turbulence can be accounted for through resistance laws analogous to those used for steady state flow.

-average channel bed slope is small so that the cosine of the angle it makes with the horizontal may be replaced by one.

De Saint-Venant equations are composed by:

The continuity equation:

$$
\frac{\partial h}{\partial t}+\frac{1}{b} \frac{\partial Q}{\partial x}=0
$$

The momentum equation:

$$
\frac{\partial Q}{\partial t}+\frac{\partial}{\partial x}\left(\frac{Q^{2}}{A}\right)+g A \frac{\partial h}{\partial x}+g A\left(S_{f}-S_{0}\right)=0
$$

These are completed by the Exner's equation, for sediment continuity:

$$
\left(1-\lambda_{p}\right) \frac{\partial \eta}{\partial t}+\frac{\partial q_{s}}{\partial x}=0
$$

where, $q_{s}$ is the sediment capacity in $\mathrm{m}^{3} / \mathrm{s}$. It is calculated by the Meyer-Peter and Müller [9] formula:

$$
q_{s}=8 \sqrt{(S-1) g d_{m}{ }^{3}}\left[\left(\frac{k_{s}}{k_{r}}\right)^{\frac{3}{2}} \tau^{*}-\tau_{c}^{*}\right]^{\frac{3}{2}}
$$

with

$$
\tau^{*}=\frac{\gamma h S_{f}}{\gamma(S-1) d_{m}}
$$

where : $\tau^{*}$ is the adimensional shear stress for grain of mean diameter $d_{m}$.

The explicit Lax finite difference scheme is used to solve the equation (1), (2) and (3) on a non-uniform grid. This numerical scheme is stable if the following Courant-Friedrich-Lewy (CFL) is satisfied in each meshpoint $i$ of the system (Roe [10]), i.e.:

$$
C r_{i}=\left(\frac{q_{i}}{h_{i}}+\sqrt{g h_{i}}\right) \frac{\Delta t}{\Delta x_{i}} \leq 1
$$

where: $q_{i}$ and $h_{i}$ are the flow per unit width $\left(\mathrm{m}^{2} / \mathrm{s}\right)$ and the water depth $(\mathrm{m})$ at the node $i$, respectively; $C r_{i}$ is the Courant number (-).

As shown above, granulometry is an important parameter in the sediment transport calculation in our model. Originally, alluvium thickness in the bed of the Loire River was about 1 meter. The sediment deficit during the last years led the river to incise substratum in some spans. Within the model, if the node $i$ corresponds to an outcrop, then using granulometry for erosion calculation is not 
appropriate. Hence, we propose a formula for bedrock incision. Momber [11] showed that the incision process could be related to factors such as: air exposure, abrasion, cavitation and other physico-chemical factors.

Sklar and Dietrich [12] developed a model for incision by abrasion wherein the wear rate depends linearly on the flux of impact kinetic energy normal to the bed and on the fraction of the bed that is not armored by transient deposits of alluvium.

In the case of the Loire River, we dismiss the cavitation. Taking into account the effects of air exposure requires a considerable amount of data. Therefore, abrasion is assumed to be still present but incision is also proportional to a power function of deviation between the hydraulic discharge $\mathrm{Q}$ and the flow to produce the sediment motion $\mathrm{Q}_{0}$.

The incision rate $\mathrm{E}(\mathrm{m} / \mathrm{s})$ is given by the following empirical equation:

where:

$$
\mathrm{E}=\mathrm{K}\left(1-\mathrm{Q}_{\mathrm{o}} / \mathrm{Q}\right)^{\beta}
$$

$Q_{0}$ : flow for sediment motion $\left(\mathrm{m}^{3} / \mathrm{s}\right)$

$Q:$ stream flow $\left(\mathrm{m}^{3} / \mathrm{s}\right)$

$\beta$ : Empirical coefficient (-)

$K$ : incision parameter (-)

\subsection{The geochemical approach}

River morphological changes are linked both to the quantity and the nature of its transported materials. The aim is to extract an estimate of the proportion of substratum incorporated in the solid load, which cannot be found by the hydraulic model due to undefined granulometry.

This method is based on material assessment: in the absence of erosion of the substratum and banks, the chemical composition of the sediment varies only in response to contributions from the riversides. On a section deprived of tributary and bank influx, any erosion must result in a longitudinal drift of the chemistry of the sediment, whose amplitude increases with the relative severity of erosion when compared to the sedimentary flux from upstream. Petrographic and chemical analyses deal with sand sampled primarily from the current channel, as in the significant sandy deposits from the 2003 flood. Samplers were placed along the considered span, in order to trace the change over time in the composition of the sediments transported.

This method is composed of 4 steps:

1/ Sampling in the bank or in sandbar: depositional zone are generally located downstream of natural obstacles (debris, knickpoint...)

2/ ICP and fluorescence-X analysis to evaluate the concentration of minor ( $\mathrm{TiO} 2, \mathrm{P} 2 \mathrm{O} 5, .$.$) , major elements \left(\mathrm{K}_{2} \mathrm{O}, \mathrm{SO}_{2}, \ldots\right)$, heavy minerals $(\mathrm{Zr}$, Ti, Cr...) and trace elements $(\mathrm{Cu}, \mathrm{Zn}, \ldots)$.

3/ Detection of the main sample constituent, using binary and ternary diagrams. In our case, 3 major constituents were found: tertiary (marl rock), quaternary, and basaltic materials. 
4/ Calculation on the amount of tertiary material eroded from the bed or brought by the tributaries in the studied zone. A material assessment is accomplished for each event. In fine, if the duration of an event is $\Delta t$, a longitudinal variation of the chemistry of the sediment, is equivalent to a time variation of the topography (equation (8)).

$$
V_{\text {sub }}^{\text {eroded }}=C_{\text {sub }}^{\text {eroded }} \frac{\Delta(\text { erosion })}{\Delta t}=\frac{C_{s u b}^{\text {in }} Q_{s}^{\text {in }}-C_{\text {sub }}^{\text {out }} Q_{s}^{\text {out }}}{\Delta x}
$$

where

$V_{\text {sub }}^{\text {eroded }}:$ is the quantity of marl rock eroded between two sampled sections per unit width $\left[\mathrm{m}^{3} / \mathrm{s} / \mathrm{m}\right]$

$C_{s u b}^{\text {in }}:$ is the upstream proportion of tertiary material (from analysis) [mol/l]

$C_{\text {sub }}^{\text {out }}$ : is the downstream proportion of tertiary material (from analysis) [mol/1]

$Q_{s}^{i n}:$ is the sediment capacity at the upstream section $\left[\mathrm{m}^{3} / \mathrm{s}\right]$

$Q_{s}^{\text {out }}:$ is the sediment capacity at the downstream section $\left[\mathrm{m}^{3} / \mathrm{s}\right]$

$\Delta t$ : is the event duration [s]

$\Delta x$ : distance between the 2 sampling sections [m]

\section{Application to the Loire River}

In this paper, we present the result of our calculation along a $9 \mathrm{~km}$ stretch between Montrond-les-Bains and La Caille (figure 1). The time period for this simulation is the year 2003 where in December a flood of $Q=2420 \mathrm{~m}^{3} / \mathrm{s}$ has been observed in the Loire River.

This part of the work is thus a sedimentary assessment and its spatial representation by our 1-D model.

It is supposed that sediment motion appears at a discharge of $Q=250 \mathrm{~m}^{3} / \mathrm{s}$.

Moreover, the following assumptions were adopted: subcritical regime (Froude number $\mathrm{Fr}<1$ ), water depth is much less than channel width $(\mathrm{b}<<\mathrm{h})$, uniform granulometry with grain of diameter $d_{m}=0.002 \mathrm{~m}$.

Boundary conditions are:

-upstream: the water discharge of the studied period (2003) and a sediment supply Qs assumed to be constant and about $15 \%$ of the sediment capacity at equilibrium.

-downstream: the surface level is assumed to be constant because this section is located in an extended area.

On figure 3 , the incision of the substratum is practically negligible in spite of the intensity of 2003 flood. That is explained by the choice of the coefficients of the incision equation (equation (7)) with $\mathrm{K}=10^{-9}$ and $\beta=0.5$. From a geomorphologic point of view, the results show that the river seeks a new slope of equilibrium (Kondolf et al. [13]). That results in a lowering, at the places where one observes breaks of slope. Moreover, the zones with weak slopes are filled by the deposits. The results of simulation thus showed that, at the scale of this event, maximum erosion was about $11 \mathrm{~cm}$ and the maximum deposit of approximately $16 \mathrm{~cm}$. 


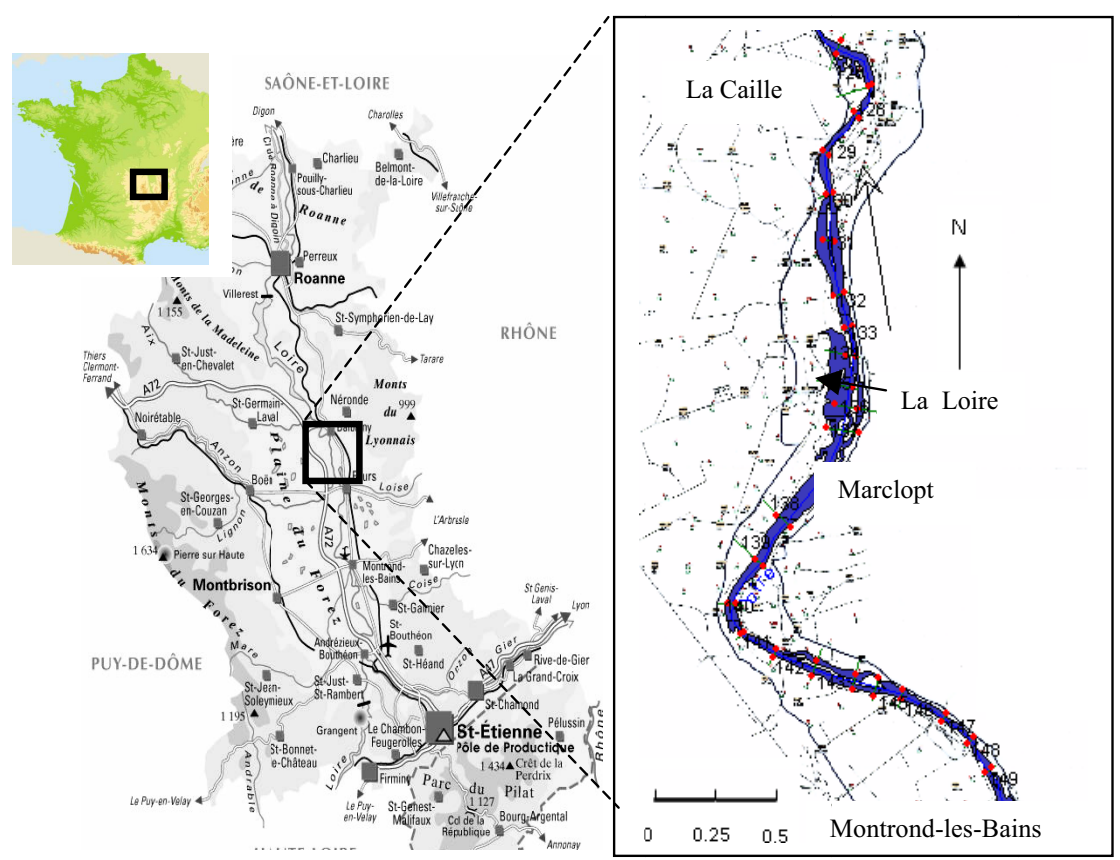

Figure 1: Map representing the Loire River in the studied reach, between Montrond-les-Bains and La Caille $(9 \mathrm{~km})$.

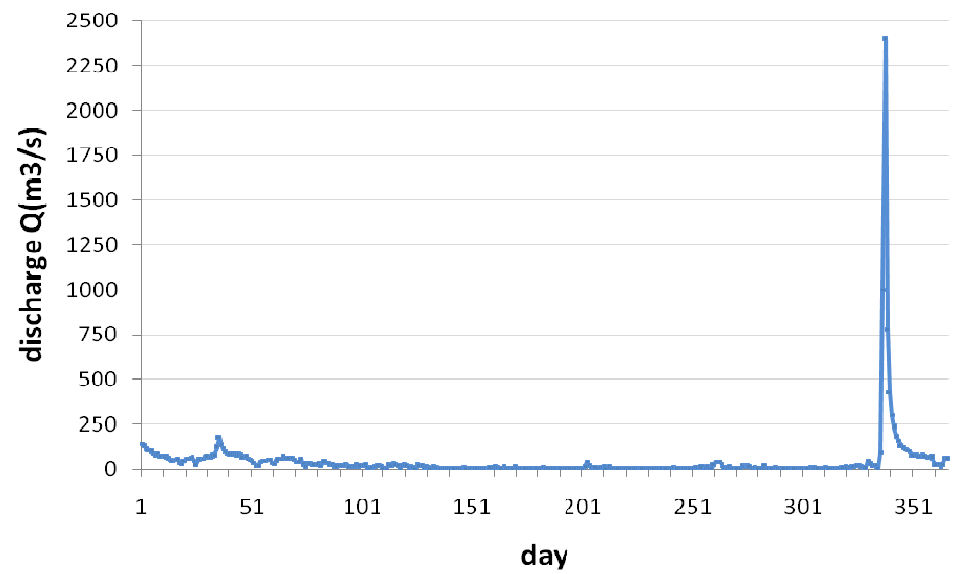

Figure 2: Daily flow hydrograph for the year 2003 at the Montrond-lesBains station (source: Banque Hydro) which serves as extreme boundary condition of the hydro-sedimentary dynamic model. 


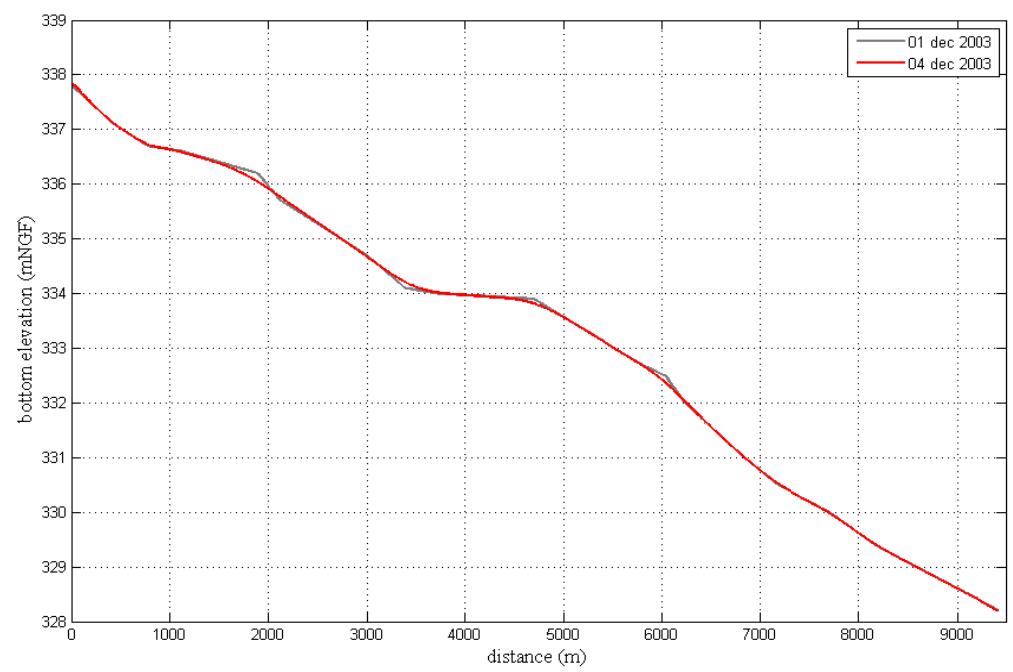

Figure 3: Longitudinal profile representing the changes over time of the bottom elevation with incision parameters $K=10^{-9}$ and $\beta=0.5$.

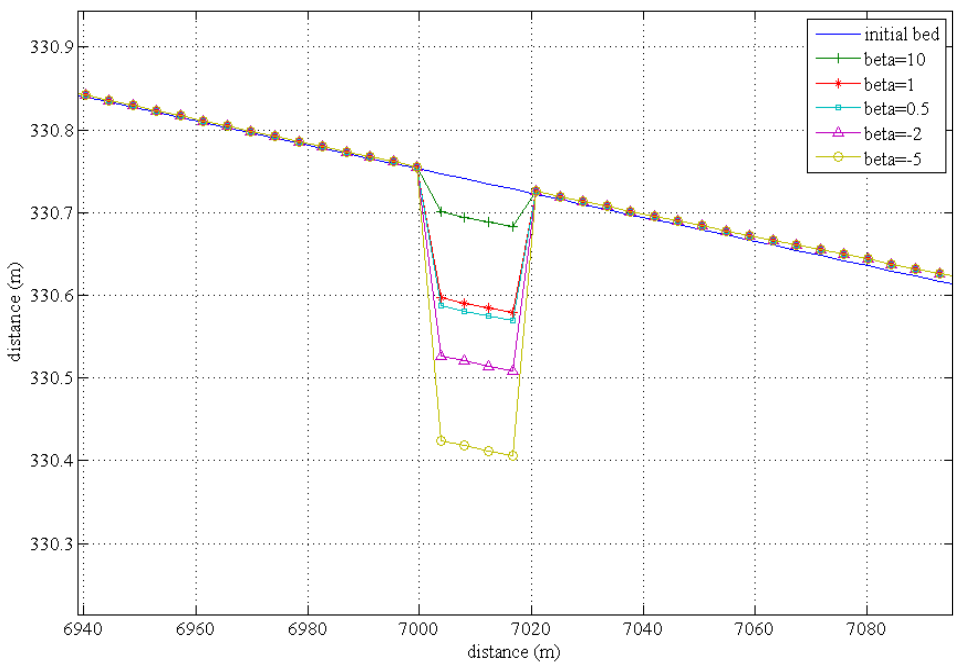

Figure 4: $\quad$ Influence of the parameter $\beta$ on bedrock incision rate calculations from distance $6.9 \mathrm{~km}$ to $7.1 \mathrm{~km}$ of the reach.

First, calibration of the incision equation is performed from the abrasion model of Sklar and Dietrich [12]. For a value of $\mathrm{K}=10^{-6}$, a sensibility test of the parameter $\beta$ was performed. Figure 4 shows that the incision rate could be amplified considerably if its value decreases. 
The values of the bed loads of the model were combined with the geochemical data. It seems that the chemical signatures of the tributaries (Lignon, Furan, Bonson) come close to more materials quaternary than of basalt. According to figure 5, the samples coming from Bonson and Lignon are not rich in calcium and their compositions are not similar to basalt elements (rich in $\mathrm{Fe}$ and $\mathrm{Mg}$ ). That means that the Eastern tributaries from the catchment erode granite (quaternary) rather than the tertiary materials.
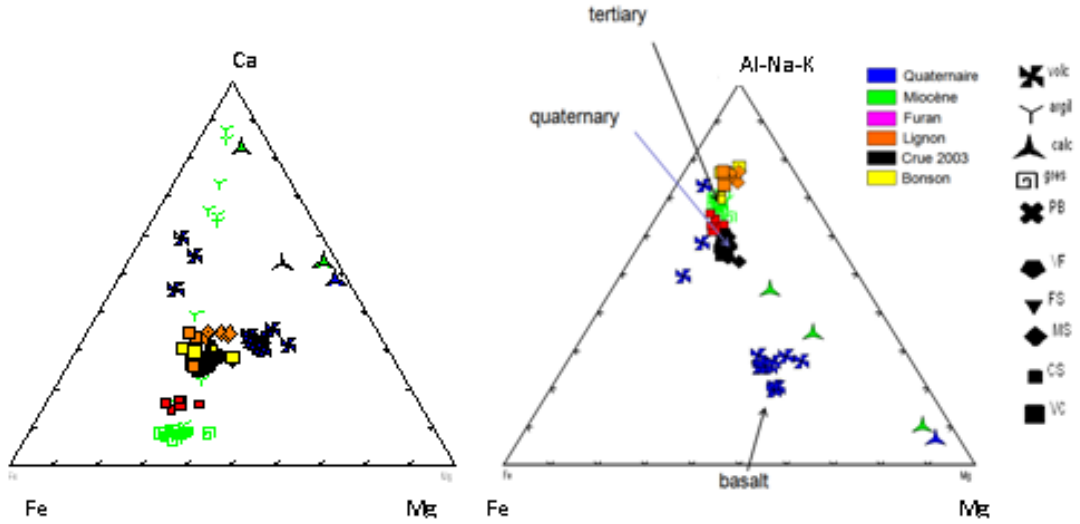

Figure 5: Ternary diagrams presenting the composition of different mixed constituents.

There are fundamental chemical contrasts among the substratum (marls Miocene) and the recent alluvia (quaternary) containing many basalt fragments on this segment of the Loire. The experience gained on the old sedimentary sequences shows that the effects of this sorting are more complex than a simple granulometric differentiation (Garcia et al. [14]). Using bed-load discharge from the hydraulic model into equation (8), we found that for this flood of 2003, the mean proportion of eroded tertiary materials is about $30 \%$ of the volume of transported materials, i.e. $3000 \mathrm{~m}^{3}$. This observation is similar to the proportions of materials in transport models with extended granulometry. Indeed, in this type of model, the transit is a mixture of approximately $30 \%$ of material coming from the active layer (in our case the substratum) and 70\% coming from the upstream i.e. the bed-load (Egiazaroff [15]; Ashida and Michiue [16]). The difference may result either from errors in the geochemical analyses and in transport capacity calculation within the hydraulic model. In fact, the assumptions of uniform granulometry, as well as the initial conditions of the model, are not adapted to our case study because armoring and grain sorting process are neglected.

\section{Conclusion}

A specific model was developed to study the Loire River. This approach was necessitated because of the characteristics of the Loire itself. Having outcrops of 
bedrock made existing models insufficient. The proposed one-dimensional model provided significant results, if the assumptions were well known and the physical laws to describe each process were correct. Generally, the validation of sediment transport models remains problematic because of the lack of easily measured data. Moreover, the granulometry which is a fundamental parameter constitutes one of the limits of these models in particular in case of bedrock river channels as in the Loire. In our study, it was possible to determine, with the assistance of geochemistry, the proportion of materials of the tertiary sector eroded in each section. Future work may include a further validation of this geochemistry method. Eventually it can be envisioned to pursue the application of this model in other river basins.

\section{Notation}

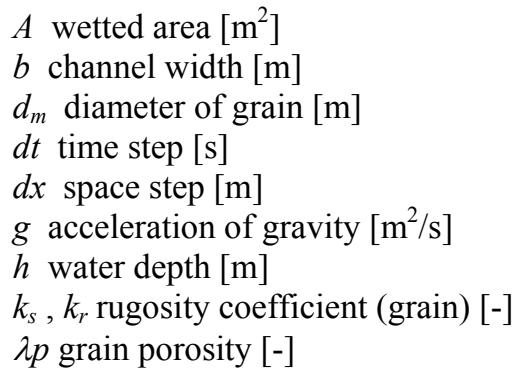

\author{
$Q$ discharge $\left[\mathrm{m}^{3} / \mathrm{s}\right]$ \\ $q_{s}$ sediment discharge per unit width \\ $\left[\mathrm{m}^{2} / \mathrm{s}\right]$ \\ $S$ relative density of grain [-], \\ $S_{o}$ bottom slope [-] \\ $S_{f}$ energy slope [-] \\ $\tau^{*}$ adimensional shear stress [-]. \\ $\tau^{*}{ }_{c}$ critical adimensional shear stress \\ $[-]$. \\ $\eta$ bottom elevation $[\mathrm{m}]$
}

\section{References}

[1] Belleudy P., Simulation numérique du dépôt sédimentaire en granulométrie étendue 1: reproduction et analyse d'un essai de laboratoire. Journal of hydraulic research, 38: 417-425, 2000.

[2] Schaller, M., Hovius, N., Willett, S.D., Ivy-Ochs, S., Synal, H.-A., and Chen, M.-C., 2005, Fluvial bedrock incision in the active mountain belt of Taiwan from in situ-produced cosmogenic nuclides. Earth Surface Processes and Landforms 30, 955-971.

[3] Bourke M.C., Suspended sediment concentrations and the geomorphic effect of sub-bankfull flow in a central Australian stream: IAHS proceeding, 276: 315-324, 2002

[4] Thomas, W.A. and Prashum, A.I., Mathematical model of scour and deposition, Journal of Hydraulic Division, 110 (11):1613-1641, 1977.

[5] Holly, F.M. and Rahuel, J.L., New numerical/physical framework for mobile-bed modeling, Part 1: numerical and physical principles. Journal of hydraulic research, 28 (4): 401-416, 1990.

[6] Hervouet J.M., A high resolution 2-D dam break model using parallelization, Hydrological processes, 14: 2211-2230, 2000. 
[7] Cunge J.A, Holly F.M., and Verwey A. Practical aspects of computational river hydraulics. Pitman Publishing Ltd. London, 1980.

[8] Soni J.P., Garde R.J., and Ranga Raju G. Aggradation in streams due to overloading. Journal of the Hydraulics Division, 106: 117-137, 1992.

[9] Meyer-Peter, Müller, "Formula for bed load transport". Proc., 2nd IAHR Congress, Stockholm, 1948.

[10] Roe P.L. Approximate Riemann solvers, parameter vectors, and difference schemes. Journal of Computational Physics, 135: 250-258, 1997.

[11] Momber A.W., wear of rocks by water flow. International Journal of Rock Mechanics and mining sciences, 41: 51-68, 2004.

[12] Sklar L.S. and Dietrich W.E. A mechanistic model for river incision into bedrock by saltating bedload. Water Resources Research, 40: 1-21, 2004.

[13] Kondolf G.M., Piégay H., and Landon N. channel response to increased and decreased bedload supply from land use change: contrasts between two catchments. Geomorphology, 45: 35-51, 2002.

[14] Garcia D., Joseph P., Maréchal B., and Moutte J. Patterns of geochemical variability in relation to turbidity facies in the Grès d'Annot Formation. The geological society of London, 2004.

[15] Egiazaroff, I. V., 1965, Calculation of non-uniform sediment concentrations, Journal of Hydraulic Engineering, 91(4), 225-248.

[16] Ashida, K. and M. Michiue, 1972, "Study on hydraulic resistance and bedload transport rate in alluvial streams, Transactions, Japan Society of Civil Engineering, 206: 59-69. 